\title{
Eksplorasi Etnomatematika pada Alat Musik Gordang Sambilan
}

\author{
Sofia Indriani Lubis ${ }^{1, \text { a) }}$, Abdul Mujib ${ }^{1, \text { b) }}$, Hasratuddin Siregar ${ }^{2}$ \\ ${ }^{1}$ Universitas Muslim Nusantara Al-Washliyah \\ Jl. Garu II no. 02 Medan Sumatera Utara. \\ ${ }^{2}$ Universitas Negeri Medan \\ ${ }^{\text {a)C} C o r r e s p o n d i n g ~ a u t h o r: ~ s o f i i n d r i a n i l u b i s @ g m a i l . c o m ~}$ \\ b)mujib_umnaw@yahoo.co.id
}

\begin{abstract}
Culture is a habit that contains essential and fundamental elements and also strongly related to human life and passed down from generation to generation. Culture can be used as a medium of learning for students at school as well as learn the culture itself. Mandailing is one of the tribes of North Sumatra that has a culture of customs, heritage, distinctive traditions, and different from other cultures that must be preserved. One of the mandailing cultures is Gordang Sambilan which is a traditional musical instrument consisting of nine drums with different height and diameter resulting in different tones and is played by 5-6 players. The purpose of this research is to explore any mathematical concepts that exist in Gordang Sambilan musical instrument so that it can be implemented on learning mathematics in the classroom. This research uses an explorative qualitative research approach on Gordang Sambilan musical instrument. The results of this study indicate that there are several types of arithmetic sequence concepts and geometric.
\end{abstract}

Keywords: Ethnomathematics, Mandailing, Gordang Sambilan, Geometry, Arithmetic.

\begin{abstract}
Abstrak. Budaya merupakan suatu kebiasaan yang mengandung unsur-unsur nilai penting dan fundamental serta dekat dengan kehidupan manusia dan diwariskan dari generasi ke generasi. Budaya dapat dijadikan sebagai media pembelajaran bagi siswa disekolah sekaligus mempelajari budaya itu sendiri. Mandailing merupakan salah satu etnik dari Sumatera Utara yang memiliki budaya adat istiadat, warisan, tradisi yang khas, dan berbeda dengan kebudayaan lain yang harus dilestarikan. Salah satu kebudayaan mandailing adalah Gordang Sambilan yaitu alat musik tradisional yang terdiri dari sembilan gendang dengan tinggi dan diameter yang berbeda sehingga menghasilkan nada yang berbeda dan dimainkan oleh 5-6 orang pemain. Tujuan dari penelitian ini untuk mengeksplorasikan konsep matematika apa saja yang ada pada alat musik Gordang Sambilan sehingga dapat diimplementasikan pada pembelajaran matematika di dalam kelas. Jenis penelitian ini adalah penelitian kualitatif yang bersifat eksploratif tentang alat musik Gordang Sambilan. Hasil dari penelitian ini menunjukkan bahwa terdapat beberapa jenis konsep barisan aritmatika dan konsep geometri.
\end{abstract}

Kata kunci: Etnomatematika, Mandailing, Gordang Sambilan, Geometri, Aritmatika..

\section{PENDAHULUAN}

Kesadaran akan pentingnya pengelolaan dan pelestarian warisan budaya kini sudah semakin tinggi. Bahkan, banyak di antara pencinta dan pemerhati warisan budaya yang berkeyakinan bahwa sumber daya budaya tidak saja sebagai warisan, melainkan sebagai pusaka bagi bangsa Indonesia (Tanudirjo, 2003).

Pendidikan dan budaya adalah dua unsur yang tidak bisa dihindarkan dalam kehidupan sehari-hari, karena budaya merupakan kesatuan utuh dan menyeluruh yang berlaku dalam suatu masyarakat dan pendidikan merupakan kebutuhan mendasar bagi setiap individu dalam masyarakat. Daoed Joesoef (dalam Putri, 2017) menyatakan bahwa kebudayaan diartikan sebagai semua hal yang terkait dengan budaya. Dalam konteks ini tinjauan budaya dilihat dari tiga 
aspek, yaitu pertama, budaya yang universal yaitu berkaitan nilai-nilai universal yang berlaku di mana saja yang berkembang sejalan dengan perkembangan kehidupan masyarakat dan ilmu pengetahuan atau teknologi. Kedua, budaya nasional, yaitu nilai-nilai yang berlaku dalam masyarakat Indonesia secara nasional. Ketiga, budaya lokal yang eksis dalam kehidupan masayarakat setempat. Sardjiyo dan Pannen (2005) mengatakan bahwa pembelajaran berbasis budaya merupakan suatu model pendekatan pembelajaran yang lebih mengutamakan aktivitas siswa dengan berbagai ragam latar belakang budaya yang dimiliki, diintegrasikan dalam pembelajaran. Bahkan hasil penelitian Fujiati (2014) menunjukkan bahwa Ppmbelajaran berbasis etnomatematika dapat meningkatkan kemampuan komunikasi matematis siswa.

Pembelajaran berbasis budaya dapat dibedakan menjadi tiga macam, yaitu belajar tentang budaya, belajar dengan budaya, dan belajar melalui budaya. Supriadi (2013) menyebutkan ada empat hal yang harus diperhatikan dalam pembelajaran berbasis budaya, yaitu substansi dan kompetensi bidang ilmu bidang studi, kebermaknaan dan proses pembelajaran, penilaian hasil belajar, serta peran budaya. Pembelajaran berbasis budaya lebih menekankan tercapainya pemahaman yang terpadu (integrated understanding) dari pada sekedar pemahaman mendalam (inert understanding). Dengan mengintegrasikan budaya dalam pembelajaran matematika, diharapkan dapat membuat siswa lebih memahami dan menghindari miskonsep matematika. Karena miskonsepsi selalu muncul dalam kegiatan belajar mengajar (Mujib, 2017). Untuk itu, melakukan kombinasi pembelajaran untuk mengoptimalkan hasil belajar merupakan salah satu alternative solusi (Mujib, 2018). Diantaranya adalah menerapkan pembelajaran berbasis budaya. Sebelum menerapkan budaya dalam pembelajaran, hal terpenting yang harus dilakukan adalah mengenal, memahami, dan mengeksplorasi budaya itu sendiri.

Indonesia merupakan negara kepulauan dengan kekayaan serta keragaman budaya, ras, suku bangsa, bahasa daerah dan masih banyak lainnya. Keragaman yang ada di Indonesia merupakan kekayaan dan keindahan bangsa Indonesia. Tiap daerah mempunyai corak dan budaya masingmasing dengan ciri khasnya, antara lain pakaian adat, bentuk rumah, kesenian, bahasa, dan tradisi lainya.

Salah satu budaya lokal yang dikenal di Indonesia adalah Budaya Mandailing yang ada di Pulau Sumatera. Mandailing merupakan nama suku sekaligus wilayah di kabupaten Mandailing Natal Sumatera Utara (Parinduri, 2013). Suku Mandailing memiliki kemiripan dengan etnik lain seperti adanya sistem marga dan penghormatan terhadap adat. Budaya Mandailing memiliki adat istiadat, warisan atau tradisi yang harus dijaga dan dilestarikan oleh generasi saat ini (Nasution, 2005). Karena kebudayaan Mandailing memiliki ciri khas tersendiri yang membedakannya dengan kebudayaan daerah lain. Sehingga kebudayaan Mandailing tetap bisa dilestarikan sebagai budaya Nasional. Adapun beberapa kebudayaan Mandailing adalah Rumah adat Bagas Godang dan Sopo Godang (Lubis, 1992), Alat musik Gordang Sambilan (Nasution, 2007), Sistem tulisan Aksara Mandailing, Kain tenun tradisioanal, Ulos/Abit Godang, dan Markobar Pidato Adat (Parinduri, 2013).

Gordang sambilan merupakan alat musik yang terkenal sebagai identitas Mandailing. Gordang artinya gendang atau bedug sedangkan Sambilan artinya sembilan. Gordang sambilan adalah satu kesenian tradisional suku mandailing yang terdiri dari sembilan gendang yang mempunyai tinggi dan diameter yang berbeda sehingga menghasilkan nada yang berbeda pula dan biasanya dimainkan oleh lima orang pemain (Parinduri, 2016b). Gordang sambilan merupakan alat musik perkusi khas mandailing ini memiliki keunikan, baik dari segi ukuran, jumlah pemain, serta irama yang berbeda dengan alat musik yang lain. 
Gordang Sambilan terbuat dari kayu yang dilubangi salah satu ujung lobangnya, kemudian ujung yang lain ditutup dengan menggunakan membran terbuat dari kulit lembu. Kulit tersebut ditegangkan dengan menggunakan rotan, yang juga berfungsi sebagai pengikat, gambar 1 dan gambar 2 menunjukkan bentuk gordang sambilan. Untuk membunyikan diperlukan pemukul dari kayu dengan pemain sebanyak 5 orang, dengan nada gendang yang paling kecil 1 sebagai enengeneng, gendang 2 tepe-tepe, gendang 3/4 kudong-kudong, gendang 5/6 paniga 7,8, dan 9 sebagai jangat. Pada praktiknya, permainan gordang sambilan diringi dengan dua buah gong, tiga buah gong kecil yang disebut mongmongan, satu gong sedang disebut doal, sepasang simbal kecil (tali sasayat), serta dengan iringan alat tiup yang disebut saleot. Dalam memainkannya biasanya dimulai dengan suara doal tiga kali, disambut dengan suara mongmongan dan gong yang semuannya terdiri atas alat musik pukul logam. Setelah itu, dibunyikan udong-kudong dan paniga, seterusnya diikuti oleh tepe-tepe dan eneng eneng. Setelah semua unsur bunyi tadi menyatu barulah dipukul suara jangat sebagai pengatur ritme dan irama (Parinduri, 2016a). Bentuk Gordang Sambilan dapat ditunjukkan pada Gambar 1.

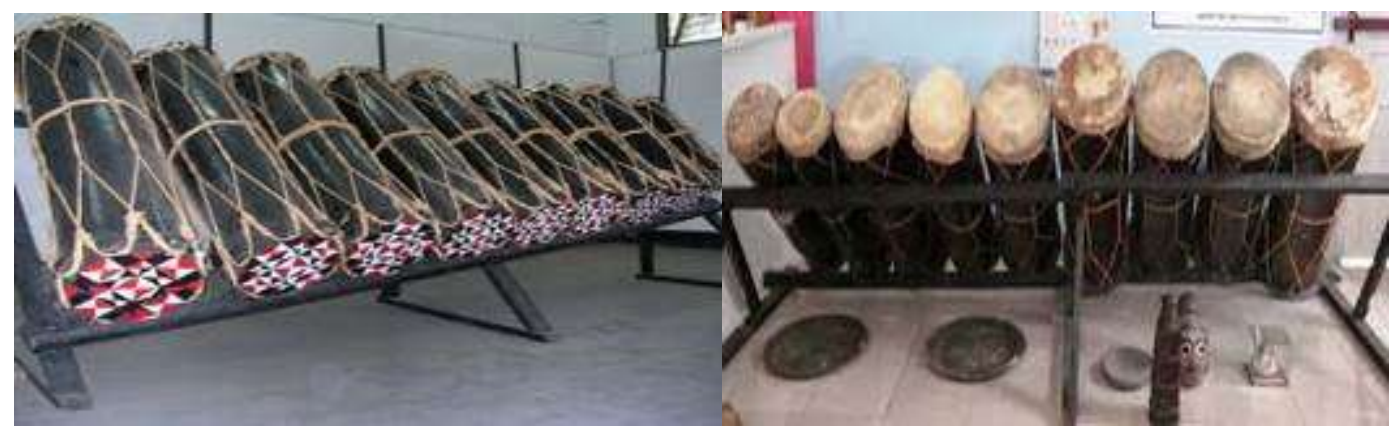

Gambar 1. Alat Musik Gordang Sambilan

Selanjutnya, bagaimana alat musik atau kesenian gordang sambilan dapat diterapkan dalam pembelajaran di dalam kelas khususnya pada pembelajan matematika? Gordang sambilan sebagai media pembelajaran matematika, perlu dikaji terlebih dahulu unsur dan konsep matematika apa yang ada pada gordang sambilan. Sehingga kajian etnomatematika tentang gordang sambilan menjadi kajian yang menarik untuk di eksplorasi lebih mendalam.

Etnomatematika di Indonesia sebenarnya bukanlah merupakan suatu ilmu pengetahuan baru melainkan sudah dikenal sejak diperkenalkan ilmu matematika itu sendiri (Putri, 2017). Namun disiplin ilmu ini disadari setelah beberapa ilmuwan memperkenalkan nama etnomatematika menjadi bagian dari ilmu matematika. Setelah itu, etnomatematika mulai dikembangkan melalui kajian berbagai keilmuan yang relevan. Oleh karena itu kini telah banyak pengembangan etnomatematika terutama pada aplikasi pembelajaran di sekolah. Wahyuni (2015) mendefinisikan bahwa etnomatematika adalah cara-cara khusus yang digunakan oleh suatu kelompok budaya atau masyarakat tertentu dalam aktivitas matematika. Dimana aktivitas matematika adalah aktivitas yang di dalamnya terjadi proses pengabstraksian dari pengalaman nyata dalam kehidupan seharihari ke dalam matematika atau sebaliknya, meliputi aktivitas mengelompokkan, berhitung, mengukur, merancang bangunan atau alat, membuat pola, membilang, menentukan lokasi, permainan, menjelaskan, dan sebagainya. Oleh karena itu, penelitian ini dilakukan untuk menjawab pertanyaan "konsep matematika apa saja yang terdapat pada alat musik gordang sambilan?" 


\section{METODE}

Penelitian ini menggunakan pendekatan kualitatif deskriptif dengan jenis penelitian lapangan atau lingkungan alamiah sebagai sumber data langsung. Penelitian lapangan mengungkap fakta kehidupan sosial dan budaya masyarakat dilapangan (Marheni, 2005). Pendekatan kualitatif merupakan prosedur penelitian yang menghasilkan data deskriptif, ucapan atau tulisan dan perilaku yang dapat diamati dari orang-orang (subyek) itu sendiri. Penelitian yang dilakukan guna menggali informasi tentang etnomatemtika pada alat musik tradisional gordang sambilan meliputi identifikasi konsep matematika yang ada dalam Gordang Sambilan. Informan dalam penelitian ini adalah pemilik gordang sambilan aktif pada grup Raptama pimpinan Mhd. Bakhsan Parinduri. Data diperoleh berdasarkan hasil wawancara serta eksplorasi langsung terhadap alat musik gordang sambilan. Alat pengumpul data adalah peniliti sendiri dengan menggunakan teknik pengumpulan data dan informasi terkait dengan rumusan masalah yang menjadi fokus dalam penelitian ini, peneliti menggunakan triangulasi data yaitu memadukan teknik observasi, wawancara dan dokumentasi

\section{HASIL DAN PEMBAHASAN}

\section{Ukuran Gordang Sambilan}

Berdasarkan hasil wawancara dan ekslorasi langsung diketahui bahwa Gordang Sambilan merupakan jati diri mandailing yang diperkirakan sudah eksis sejak beberapa abad lalu, dan sudah dimainkan sebagai alat musik religi jauh sebelum agama islam menjadi agama mayoritas orang Mandailing. Ensambel Gordang Sambilan terbuat dari kayu yang dilubangi salah satu ujung lobangnya, kemudian ujung yang lain ditutup dengan menggunakan membran terbuat dari kulit lembu. Kulit tersebut ditegangkan dengan menggunakan rotan, yang juga berfungsi sebagai pengikat. Untuk membunyikan diperlukan pemukul dari kayu dengan pemain sebanyak 5 orang.

Gordang Sambilan ini terdiri atas sembilan gendang besar dan tinggi. Gendang yang paling kecil (gendang 1) bergaris tengah $20 \mathrm{~cm}$, gendang yang kedua bergaris tengah $25 \mathrm{~cm}$, gendang yang ketiga bergaris tengah $30 \mathrm{~cm}$ demikian seterusnya semakin besar dengan selisih garis tengah 5 $\mathrm{cm}$ gendang yang paling besar bergaris tengah $60 \mathrm{~cm}$. Begitu juga dengan tinggi gendang dari gendang terkecil tingginya sekitar $120 \mathrm{~cm}$ sampai dengan $160 \mathrm{~cm}$. Pada hakikatnya, perbedaan ukuran garis tengah dengan ukuran tinggi gordang mengakibatkan terjadinya variasi bunyi yang mirip lebih kurang seperti perbedaan dalam tangga nada. Di samping perbedaaan ukuran tersebut di atas, perbedaan bunyi juga dapat dihasilkan dengan keketatan tarikan tali rotan yang diikatkan pada membran kulit.

Hasil eksplorasi bentuk etnomatematika pada kesenian alat musik gordang sambilan telah menggunakan konsep dasar geometri yang diterapkan dalam bentuknya. Ensambel ini terdiri atas sembilan gendang besar dan tinggi berbentuk seperti tabung atau Kerucut terpancung. Gendang yang paling kecil (gendang 1) bergaris tengah $20 \mathrm{~cm}$, gendang yang kedua bergaris tengah $25 \mathrm{~cm}$, gendang yang ketiga bergaris tengah $30 \mathrm{~cm}$ demikian seterusnya semakin besar dengan selisih garis tengah $5 \mathrm{~cm}$ gendang yang paling besar bergaris tengah $60 \mathrm{~cm}$. Begitu juga dengan tinggi gendang dari gendang terkecil tingginya sekitar $120 \mathrm{~cm}$ sampai dengan $180 \mathrm{~cm}$. 


\section{Konsep Geometri pada Gordang Sambilan}

Hasil eksplorasi etnomatematika pada alat musik gordang sambilan diketahui bahwa bentuk fisik Gordang Sambilan terdapat dua jenis bentuk geometri bangun ruang yaitu berbentuk tabung dan kerucut terpancung.

\section{Tabung Gordang Sambilan}

Gordang Sambilan sebagai tabung artinya luas sisi alas dan atap identik. Berdasarkan hasil pengukuran langsung, diketahui bahwa Gordang sambilan mempunyai ukuran tinggi dari gordang terkecil sampai terbesar yaitu 120, 125, 130, 135, 140, 145, 150, 155, $160 \mathrm{~cm}$ dan diameter yang berukuran mulai dari gordang terkecil sampai terbesar masing-masing 20, 25, 30, 35, 40, 45, 50, $55,60 \mathrm{~cm}$. Bentuk Gordang Sambilan menyerupai ruang tiga dimensi tabung. Gambar 2 merupakan Gordang Sambilan sebagai tabung yang kami diberi nama Tabung Gordang Sambilan.
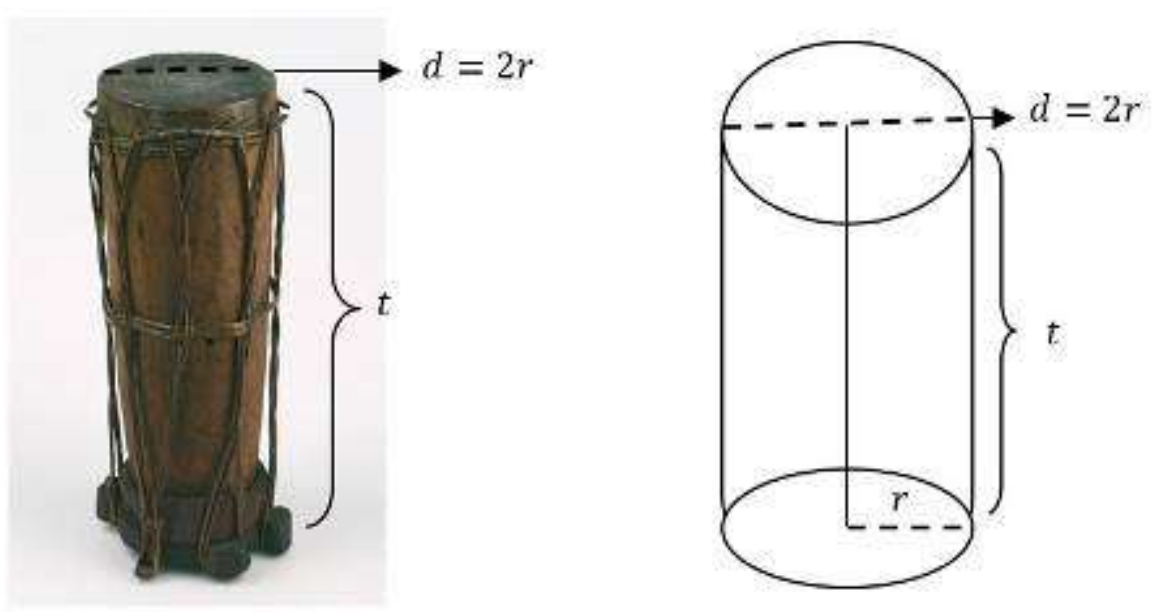

Gambar 2. Tabung Gordang Sambilan

Selanjutnya, dilakukan pengukuran keliling alas/atap, luas selimut, dan volume Tabung Gordang Sambilan. Hasil penghitungan tabung Gordang Sambilan dapat ditunjukan pada Tabel 1 berikut ini:

Tabel 1. Hasil Pengukuran Tabung Gordang Sambilan

\begin{tabular}{c|c|c|c|c|c|c}
\hline $\begin{array}{c}\text { Gordang } \\
\text { Sambilan }\end{array}$ & $\begin{array}{c}\text { Tinggi } \\
\text { gordang }(\mathrm{cm})\end{array}$ & $\begin{array}{c}\text { Diameter } \\
(\mathrm{cm})\end{array}$ & $\begin{array}{c}\text { Jari-Jari } \\
(\mathrm{cm})\end{array}$ & $\begin{array}{c}\text { Keliling } \\
(\mathrm{cm})\end{array}$ & $\begin{array}{c}\text { L. Selimut } \\
\left(\mathrm{cm}^{2}\right)\end{array}$ & $\begin{array}{c}\text { Volume } \\
\left(\mathrm{cm}^{3}\right)\end{array}$ \\
\hline 1 & 120 & 20 & 10 & 62 & 7.440 & 37.714 \\
\hline 2 & 125 & 25 & 12,5 & 78 & 9.750 & 61.383 \\
\hline 3 & 130 & 30 & 15 & 94 & 12.220 & 91.928 \\
\hline 4 & 135 & 35 & 17,5 & 110 & 14.850 & $129 . .937$ \\
\hline 5 & 140 & 40 & 20 & 126 & 17.640 & 176.000 \\
\hline 6 & 145 & 45 & 22,5 & 141 & 20.445 & 230.705 \\
\hline 7 & 150 & 50 & 25 & 157 & 23.550 & 294.642 \\
\hline 8 & 155 & 55 & 27,5 & 173 & 26.815 & 368.401 \\
\hline 9 & 160 & 60 & 30 & 189 & 30.240 & 452.571 \\
\hline
\end{tabular}


Berdasarkan tabel 1, terlihat bahwa terdapat pola menarik pada tinggi, diameter, Jari-jari, dan keliling alas Tabung Gordang Sambilan. Dimana setiap bilangannya memiliki selisih bilangan tertentu.

\section{Kerucut Terpancung Gordang Sambilan}

Bentuk gordang sambilan menyerupai kerucut terpancung yaitu kerucut yang dipotong oleh sebuah bidang sejajar dengan bidang alas. Gordang Sambilan disebut dengan Kerucut Terpancung karena memiliki ukuran alas dan atap yang berbeda. Sehingga kita namakan dengan Kerucut Terpancung Gordang Sambilan. Hasil pengukuran langsung diperoleh bahwa Gordang Sambilan mempunyai diameter atas dari gordang terkecil sampai terbesar masing-masing 20, 25, 30, 35, 40, 45, 50, 55, $60 \mathrm{~cm}$ dan diameter alas 17, 22, 27, 32, 37, 42, 47, 52, $57 \mathrm{~cm}$. Gambar 3 menunjukkan ilustrasi Kerucut Terpancung Gordang Sambilan.
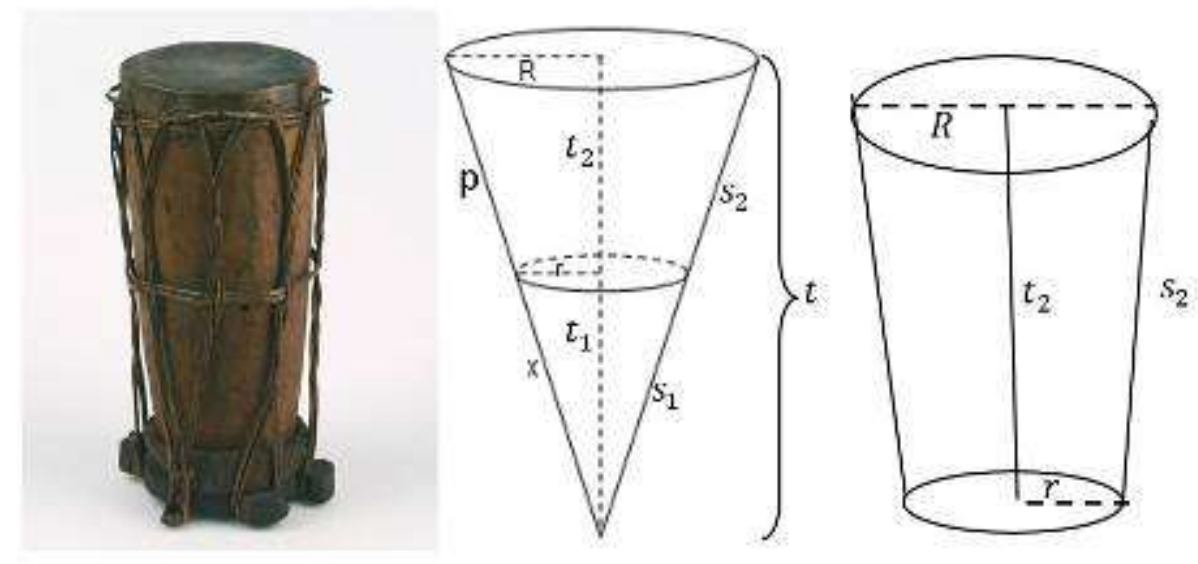

Gambar 3. Kerucut Terpancung Gordang Sambilan
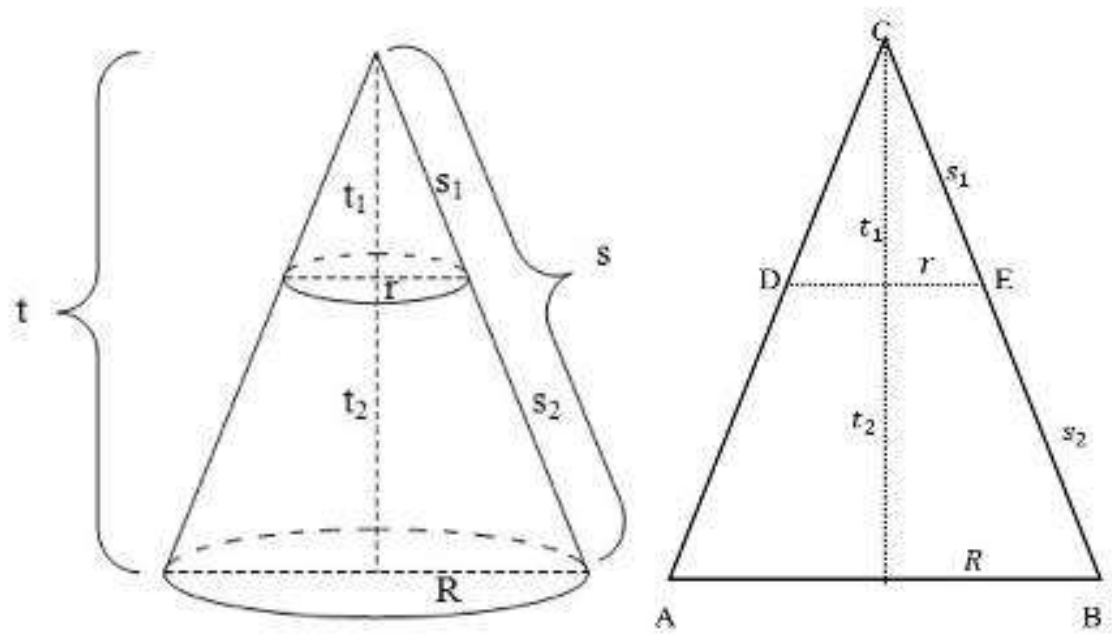

Gambar 4. Penampang Irisan Kerucut

Terlebih dahulu, akan ditentukan rumus untuk menghitung Volume dan Luas permukaan Kerucut Terpancung Gordang Sambilan. Perhatikan segitiga ABC pada Gambar 4, Segitiga ABC merupakan penampang bidang datar dari kerucut. Berdasarkan segitiga $\mathrm{ABC}$ dan segitiga $\mathrm{CDE}$, diketahui tinggi segitiga ABD dan CDE masing-msaing adalah $t \_1+t \_2$ dan $t \_1$ sedangkan $t \_2$ merupakan tinggi kerucut terpancung, panjang sisi $\mathrm{BC}$ dan EC masing-masing $\mathrm{s}_{-} 1+\mathrm{s}_{-} 2$ dan $\mathrm{s}_{-} 1$ sedangkan $s \_2$ merupakan panjang garis pelukis kerucut terpancung, dan panjang $\mathrm{R}$ dan $\mathrm{r}$ masing- 
masing adalah 1/2 AB dan 1/2 EF merupakan jari-jari kerucut. Karena segitiga ABC dan segitiga CDE sebangun, maka didapatkan perbandingan kesebangunan dari sisi-sisinya sebagai berikut.

$$
\frac{s_{1}}{s_{1}+s_{2}}=\frac{t_{1}}{t_{1}+t_{2}}=\frac{r}{R}
$$

Berdasarkan (1) didapatkan hubungan $t_{1}$ terhadap $t_{2}, r$, dan $R$ dan hubungan $s_{1}$ terhadap $s_{2}, r$, dan $R$ sebagai berikut..

$$
t_{1}=\frac{t_{2} r}{R-r}
$$

dan

$$
s_{1}=\frac{s_{2} r}{R-r}
$$

Misalkan $V$ adalah volume kerucut terpancung, $V_{R}$ dan $V_{r}$ masing-masing adalah volume kerucut berjari-jari $R$ dan volume kerucut berjari-jari $r$. Maka volume kerucut terpancung diperoleh sebagai berikut.

$$
V=V_{R}-V_{r}=\frac{1}{3} \pi R^{2}\left(t_{1}+t_{2}\right)-\frac{1}{3} \pi r^{2} t_{1}
$$

Subtitusi (2) pada persamaan (4) sehingga diperoleh rumus volume kerucut terpancung sebagai berikut

$$
V=\frac{1}{3} \pi t_{2}\left(R^{2}+r^{2}+R r\right)=\frac{1}{3} \pi t_{2}\left[(R+r)^{2}-R r\right]
$$

Dengan argument yang sama, diperoleh rumus luas selimut kerucut terpancung yaitu

$$
L=\pi s_{2}(R+r)
$$

dimana $t_{2}$ adalah tinggi kerucut terpancung dan $s_{2}$ adalah panjang garis pelukis kerucut terpancung.

Selanjutnya, dilakukan perhitungan volume dan luas selimut kerucut terpancung Gordang Sambilan yang mana sebelumnya telah dilakukan pengukuran langsung terhadap diameter atap dan diameter alas serta tinggi dari kerucut terpanjung Gordang Sambilan. Rangkuman hasil perhitungan ditunjukkan pada Tabel 2 berikut ini:

\begin{tabular}{c|c|c|c|c|c|c|c|c|c}
\multicolumn{8}{c}{ Tabel 2 Hasil Pengukuran dan Perhitungan Kerucut Terpancung Gordang Sambilan } \\
\hline $\begin{array}{c}\text { Gordang } \\
\text { sambilan }\end{array}$ & $t(\mathrm{~cm})$ & $\begin{array}{c}d \text { atap } \\
(\mathrm{cm})\end{array}$ & $R(\mathrm{~cm})$ & $\begin{array}{c}d \text { alas } \\
(\mathrm{cm})\end{array}$ & $\mathrm{r}(\mathrm{cm})$ & $K$ alas & $S(\mathrm{~cm})$ & $L$ & $V(\mathrm{~cm})$ \\
\hline 1 & 120 & 20 & 10 & 17 & 8,5 & 62 & 121 & 7.035 & 32.339 \\
\hline 2 & 125 & 25 & 12,5 & 22 & 11 & 78 & 126 & 9.306 & 54.312 \\
\hline
\end{tabular}




\begin{tabular}{c|c|c|c|c|c|c|c|c|c}
\hline 3 & 130 & 30 & 15 & 27 & 13,5 & 94 & 131 & 11.734 & 83.0442 \\
\hline 4 & 135 & 35 & 17,5 & 32 & 16 & 100 & 136 & 14.319 & 119.111 \\
\hline 5 & 140 & 40 & 20 & 37 & 18,5 & 116 & 141 & 17.182 & 163.134 \\
\hline 6 & 145 & 45 & 22,5 & 42 & 21 & 132 & 146 & 20.097 & 215.660 \\
\hline 7 & 150 & 50 & 25 & 47 & 23,5 & 147 & 152 & 23.169 & 277.313 \\
\hline 8 & 155 & 55 & 27,5 & 52 & 26 & 163 & 157 & 26.398 & 348.670 \\
\hline 9 & 160 & 60 & 30 & 57 & 28,5 & 179 & 162 & 29.785 & 430.322 \\
\hline
\end{tabular}

Berdasarkan Tabel 2, terlihat bahwa tinggi dan diameter Gordang Sambilan membentuk barisan aritmatika, maka jari-jari dan keliling lingkaran alas serta atapnya juga membentuk barisan aritmatika.

\section{Barisan Aritmatika Gordang Sambilan}

Berdasarkan eksplorasi tabung Gordang Sambilan serta kerucut terpancung Gordang Sambilan, diperoleh konsep barisan aritmatika. Barisan Aritmatika adalah suatu barisan dengan selisih (beda) dua suku yang berurutan selalu tetap. Bentuk Umum barisan aritmatika $a, a+b, a+2 b, a+3 b, \ldots, a+(n-1) b$, dimana $u_{n}-u_{n-1}=b$ sehingga diperoleh $u_{n}=u_{n-1}+b=a+(n-1) b$.

Berdasarkan Tabel 1 diketahui bahwa ukuran tinggi dan diameter Tabung Gordang Sambilan membentuk sebuah barisan aritmatika dimana selisih (beda) dua suku yang berurutan selalu tetap. Akibatnya, barisan jari-jari dan keliling alas Tabung Gordang Sambilan juga membentuk barisan aritmatika. Rumus umum dari barisan aritmatika yang didapat dari ukuran tinggi, diameter, jari-jari dan keliling lingkaran alas Tabung Gordang Sambilan dapat dirangkum pada Tabel 3 berikut:

\begin{tabular}{c|l|c|c|c}
\multicolumn{4}{c}{ Tabel 3. Barisan Aritmatika Tinggi, Diameter, Jari-jari, dan Keliling Tabung Gordang Sambilan } \\
\hline NO & \multicolumn{1}{|c|}{ Nama Barisan } & Suku Pertama (a) & Beda (b) & $\begin{array}{c}\text { Rumus Suku Ke-n } \\
U_{n}=a+(n-1) b\end{array}$ \\
\hline 1 & Barisan tinggi & 120 & 5 & $U_{n}=5 n+115$ \\
\hline 2 & Barisan diameter & 20 & 5 & $U_{n}=5 n+15$ \\
\hline 3 & Barisan jari-jari & 10 & 2,5 & $U_{n}=2,5 n+7,5$ \\
\hline 4 & Barisan keliling & 62 & 16 & $U_{n}=16 n+46$ \\
\hline
\end{tabular}

Selanjutnya, berdasarkan Tabel 2 diperoleh rumus umum dari barisan aritmatika yang didapat dari ukuran tinggi, diameter atap dan alas, jari-jari atap dan alas, keliling lingkaran atap dan alas, dan selimut kerucut terpancung Gordang Sambilan yang telah dirangkum pada Tabel 4 berikut: 
Tabel 4. Barisan Aritmatika Kerucut Terpancung Gordang Sambilan

\begin{tabular}{c|l|c|c|c}
\hline NO & \multicolumn{1}{|c|}{ Nama Barisan } & Suku Pertama (a) & Beda (b) & $\begin{array}{c}\text { Rumus Suku Ke-n } \\
U_{n}=a+(n-1) b\end{array}$ \\
\hline 1 & Barisan tinggi & 120 & 5 & $U_{n}=5 n+115$ \\
\hline 2 & Barisan diameter atap & 20 & 5 & $U_{n}=5 n+15$ \\
\hline 3 & Barisan jari-jari atap & 10 & 2,5 & $U_{n}=2,5 n+7,5$ \\
\hline 4 & Barisan keliling atap & 62 & 16 & $U_{n}=16 n+46$ \\
\hline 6 & Barisan diameter alas & 17 & 5 & $U_{n}=5 n+12$ \\
\hline 7 & Barisan keliling alas & 8,5 & 2,5 & $U_{n}=2,5 n+6$ \\
\hline 8 & Barisan selimut & 62 & 16 & $U_{n}=16 n+46$ \\
\hline
\end{tabular}

\section{Pembahasan}

Alat musik Gordang Sambilan sebagai salah satu budaya mandailing dapat di aplikasikan dalam pembelajaran matematika yaitu dengan melihat bentuk Gordang Sambilan yang menyerupai tabung dan kerucut terpancung. Ini dapat dijadikan alat untuk memperkenalkan konsep-konsep matematika seperti konsep geometri sehingga dalam memahami konsep matematika yang bersifat abstrak siswa dapat dengan mudah memahaminya. Selain itu, eksplorasi tentang diameter (garis tengah) atap, diameter alas, jari-jari atas, jari-jari alas, keliling atas, keliling atas, luas lingkaran, luas permukaan tabung, volume tabung, luas permukaan kerucut terpancung dan volume kerucut terpancung juga dapat dilakukan. Dimana ukuran-ukuran dari ke-9 Gordang Sambilan membentuk barisan aritmatika. Dengan mengekplorasi budaya sebagai media pada pembelajaran diharapkan siswa dapat lebih mudah memahami pembelajaran, juga dapat menumbuhkan sikap kecintaan akan budaya serta melestarikan budaya melalui pembelajaran di sekolah.

\section{KESIMPULAN}

Hasil eksplorasi konsep matematika pada alat musik gordang sambilan ditemukan berupa bentuk fisik yaitu konsep dasar geometri yaitu, lingkara, tabung, kerucut, dan kerucut terpancung. Sedangkan ukuran jari-jari atap dan alas, diameter atap dan alas, tinggi, keliling dan selimut gordang sambilan membentuk pola barisan aritmatika dimana selisih (beda) dua suku yang berurutan selalu tetap. Konsep-konsep matematika yang terdapat pada alat musik gordang sambilan dapat dimanfaatkan untuk memperkenalkan matematika melalui budaya lokal sehingga pembelajaran matematika di kelas akan lebih bermakna.

Untuk selanjutnya, dapat dilakukan eksplorasi konsep matematika dari cara memainkan gordang sambilan. Selain itu perlu dikembangkan penelitian dalam membuat perangkat pembelajaran matematika berbasis Budaya Mandailing khususnya Gordang Sambilan. 


\section{UCAPAN TERIMA KASIH}

Kami ucapkan terima kasih kepada Bapak Mhd. Bakhsan Parinduri sebagai budayawan mandailing dan pimpinan grup Raptama yang telah memberikan informasi sebanyak-banyaknya tentang Gordang sambilan kepada kami tim peneliti.

\section{DAFTAR RUJUKAN}

Fujiati, I. (2014). Keefektifan Model Pogil Berbantuan Alat Peraga Berbasis Etnomatematika Terhadap Kemampuan Komunikasi Matematis. Unnes Journal of Mathematics Education, 3(3).

Lubis, M, L. (1992). Sopo Godang Mandailing. Medan.

Marheni. (2005). Metode Penelitian. Jakarta: Bumi Aksara.

Mujib, A. (2017). Identifikasi Miskonsepsi Mahasiswa Menggunakan CRI pada Mata Kuliah KalkuluS II. Jurnal Mosharafa, 6(2), 181-192.

Mujib, A. (2018, April). Konflik Kognitif dalam Pembelajaran Kalkulus II. Dalam Prosiding Seminar Nasional Hasil Penelitian (Vol. 1, No. 1, pp. 87-96).

Nasution, E. (2007). Tulila: muzik bujukan Mandailing. Areca Books.

Nasution, P. (2005). Adat Budaya Mandailing dalam Tantangan Zaman. Medan: Forkala.

Parinduri, M.B. (2013). Mangirurut Novel Budaya Mandailing. Medan: Deli Grafika.

Parinduri, M.B. (2016a). Gordang Sambilan sebagai Identitas Mandailing. Medan: Pusaka Mandailing.

Parinduri, M.B. (2016b). Ensambel Gordang Sambilan. Artikel. Medan: Pusaka Mandailing.

Putri, L.I, (2017). Eksplorasi Etnomatematika Kesenian Rebana Sebagai Sumber Belajar Matematika pada Jenjang MI. Jurnal Ilmiah Pendidikan Dasar. 4(1).

Wahyuni, I. (2015). Eksplorasi Etnomatematika Masyarakat Sidoarjo. Fenomena (Jurnal Penelitian Islam Indonesia), 15(2), 225-238.

Sardjiyo \& Pannen, P. (2005). Pembelajaran Berbasis Budaya: Model Inovasi Pembelajaran dan Implementasi Kurikulum Berbasis Kompetensi. Jurnal pendidikan, 6(2), 83-98.

Supriadi, M. P. (2013). Pembelajaran Etnomatematika dengan Media Lidi dalam Operasi Perkalian Matematika untuk Meningkatkan Karakter Kreatif dan Cinta Budaya Lokal Mahasiswa PGSD, makalah seminar nasional. Pendidikan Matematika SPS UPI.

Tanudirjo, D. A. (2003). Warisan Budaya untuk Semua: Arah Kebijakan Pengelola Warisan Budaya Indonesia di Masa Mendatang. Makalah disampaikan pada Kongres Kebudayaan V, Bukittinggi, 19-23. 